\title{
Present day problems with historic innovations
}

\author{
R. Brueckner \& P. Lambert \\ Mott MacDonald, Materials \& Corrosion Engineering, UK
}

\begin{abstract}
Construction methods and building materials have been in development since the dawn of civilisation. Simple timber and stone dwellings were followed by more modern construction methods such as fired clay and mortars with continual development until the present day. Early evidence of the use of concrete dates back at least 7,000 years and there has since been a continuous timeline, through the development of pozzolanic concrete by the Romans, to the first patent for Portland cement at the beginning of the $19^{\text {th }}$ Century. Portland cement based concrete has undergone many developments based on field experience and extensive research to improve the performance of the resultant concrete, not always successfully. To reduce construction time, calcium chloride has been used as a set accelerator since 1873. This then state-of-the-art admixture has since caused significant damage due to chloride-induced corrosion of embedded reinforcement. Concretes based on other binders also appeared, such as high alumina cement (HAC) which was patented in 1908 but is now all but banned for structural use in many countries due to a number of high profile failures. This paper will discuss a number of once state-of-the-art building materials which may still be encountered in the renovation of heritage structures, and the methods and precautions required when carrying out remediation.
\end{abstract}

Keywords: concrete, calcium chloride, high alumina cement, super-sulphated, asbestos, corrosion, repair.

\section{Introduction}

Building materials have been appeared, developed and been replaced by innovations throughout millennia. The earliest development of concrete as a building material can be dated back to $5600 \mathrm{BC}$ on the Balkan Peninsula. More widespread and considered use is recorded from $3000 \mathrm{BC}$ onwards (Schaeffer [1]). In Egypt a mud consisting of lime and gypsum was employed which also 
contained straw as reinforcement. The Assyrians and Babylonians used clay as the bonding substance. In China a 'cementitious' material containing bamboo was used to construct the Great Wall. This type of mortar consisted of rice flour and slaked lime, a common mortar component (Moore [2]).

Probably the most famous concrete structure from ancient times is the Pantheon in Rome which was built in 120 AD. During the Roman Empire concrete had undergone various significant developments. From 300 BC Romans used a mixture of slaked lime and volcanic ash from Pozzouli, a small town close to the Vesuvius. The addition of lime to the ash initiated a complex hydration reaction to form calcium-silicate-hydrates and the first pozzolanic material.

After the fall of the Roman Empire the formulation of such advanced concretes was lost for more than a millennium until the $18^{\text {th }}$ Century, defined by John Smeaton's development of a hydraulic cement for use in the construction of the Eddystone Lighthouse off the south west coast of England (Figure 1). The rise of modern Western civilizations, beginning with the great migrations to North America and the subsequent industrialisation required the development of stronger, durable and more readily available building materials. The existing brick, stone and timber construction methods were sufficient until the demand rose for even faster methods.

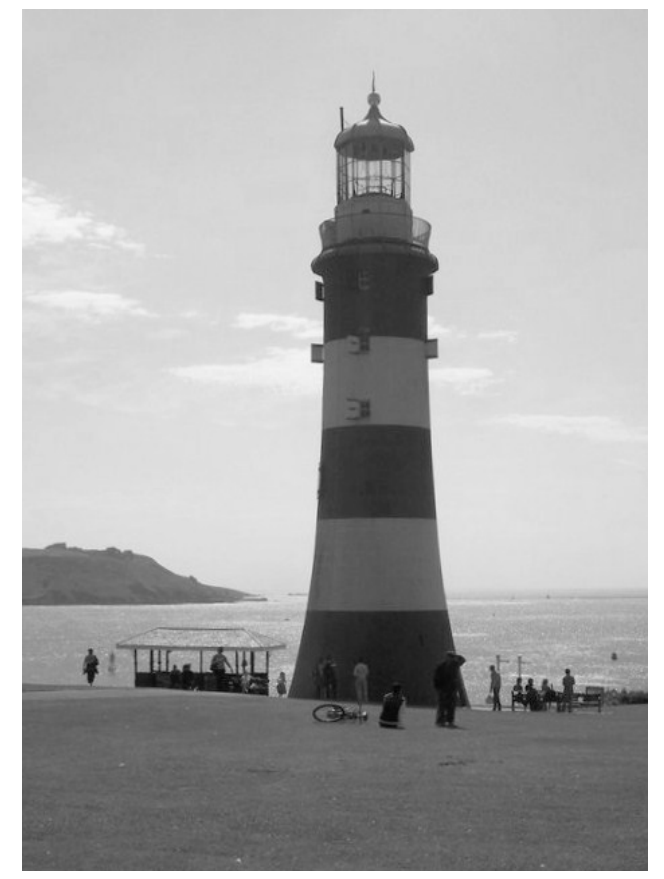

Figure 1: Smeaton's Eddystone Lighthouse, completed 1759, relocated 1877 (Photo: Lewis Clark). 
The construction of the Bridgewater canal in the North West of England and its extraordinary success led to widespread improvements in the transport system of Britain and later in the British colonies of North America. The challenges imposed during the planning and construction of the $584 \mathrm{~km}$ Erie Canal required the development of a plentiful and rapidly constructed watertight material. Modern concrete was born when Joseph Aspdin, a Leeds bricklayer and mason, patented Portland cement in 1824. He created the first mass-produced and widely accepted artificial cement by burning ground limestone and clay together. The basic recipe of Portland cement has remained largely unchanged until the present day and forms the basis of most concretes and hydraulic mortars.

Reinforced concrete, or ferroconcrete, containing embedded steel reinforcement appears to have been invented by Joseph Monier in 1849 but was not patented until 1867 [3]. Monier was a gardener from Paris who built garden pots of concrete with an iron mesh. Later he promoted the use of reinforced concrete for pipes, floors, arches and bridges.

Other types of cement were developed at the beginning of the $20^{\text {th }}$ Century which have been used in the construction of concrete structures, usually with only limited success. This may have been due to the dominance and reliability of Portland cement concretes and the problems in their use that were often encountered.

The integrity and durability of structures has been an important requirement throughout civilisation. The first recorded rules for builders were introduced by King Hammurabi in Babylon around $1700 \mathrm{BC}$ and did not change greatly until the Middle Ages in Europe. The code of Hammurabi [4] states in paragraphs 228-231:

- Paragraph 228. If a builder has built a house for a man, and finished it, he shall pay him a fee of two shekels of silver, for each SAR built on.

- Paragraph 229. If a builder has built a house for a man, and has not made his work sound, and the house he built has fallen, and caused the death of its owner, that builder shall be put to death.

- Paragraph 230. If it is the owner's son that is killed, the builder's son shall be put to death.

- Paragraph 231. If it is the slave of the owner that is killed, the builder shall give slave for slave to the owner of the house.

Around 15 BC Vitruvius wrote 'De Architectura', a ten volume treatise on architecture and construction which served as guidance on building projects in the Roman Empire. The books provide information about Roman building methods as well as the planning and design of structures. The books include sections on a wide range of topics such as town planning, architecture and civil engineering in general, building materials, civil and domestic buildings, water supply systems as well as fundamental mathematical and engineering knowledge and give advice on the use and construction of machines. In his books Vitruvius advises the avoidance of lead in drinking water systems although it took a further 2000 years until such advice was adopted in the United States.

The next important series of books on building and architecture did not appear until 1452 when Alberti compiled and published 'De re aedificatoria' (On 
the art of building) which is based on Vitruvius books with a critical review of contemporary influences from the renaissance.

The Industrial Revolution in Britain coincided with a construction boom which called for regulations to cope with the many construction methods and materials available. Over a Century later British Standards were introduced by the British Standard Institution (BSI) in 1901. The requirements for a durable concrete construction were clearly laid out in cement and concrete standards as well as in codes of practice for concrete structures and county council by-laws. Such standards and codes have been revised, updated and, where appropriate, also withdrawn over the years. Innovations, such as calcium chloride based set accelerators, high alumina cement and super-sulphated cement came in and out of standards as their benefits were recognised and limitations identified.

\section{Calcium chloride}

\subsection{General}

Concretes and mortars are generally three-phase systems consisting of a binding material (cement), aggregates and water. The fine and coarse aggregates may comprise three quarters of the volume of concrete and their maximum size governs the classification into concrete or mortar. The latter typically has a maximum aggregate size of $4 \mathrm{~mm}$ whereas there is no limitation for concrete. Nowadays, concrete is more regularly a five-phase system because of the addition of additives and admixtures for property improvement and cost reduction.

Admixtures have been used since the introduction of concrete. The Romans used blood, pig's fat and milk as additions to improve workability and durability. Calcium chloride is an accelerating admixture that is added to concrete either to increase the rate of early strength development or reduce the setting time, particularly in cold weather. Such positive effects of calcium chloride on fresh concrete have been known of since 1873 (Kuhl and Ullrich [5]) and the first patent is from 1885 by Millar and Nichols [6]. This accelerator has been the most common in construction, however, its negative effects on the durability of the reinforced concrete has led to the use of more synthetic accelerators in the presence.

\subsection{Beneficial short term effects}

The corrosive effects of chlorides on metal have been known and studied since metallic materials were used in the construction of ships. In the case of concrete calcium chloride was added to improve the properties of concrete in the short term, i.e. during the construction phase. It was particularly used to enable concreting in cold weather conditions and to speed up the construction process in general. The positive short term effects for the industry dominated any long term durability issues. 
Extensive research was conducted into the effects of chloride admixtures, in particular by the Department of Scientific and Industrial Research in the UK after World War II. The Cement and Concrete Association published several advice notes for good concrete practice which also included the use of calcium chloride. In the report of the Building Research Board [7] from 1949 it is stated that "the addition of various percentages of calcium chloride gave a marked increase in hydration at early ages, the difference between the control specimens and those containing calcium chloride becoming smaller after 21 days, and becoming insignificant at 90 days". In respect to the corrosive effects the Board states that "So far, the amount of corrosion is small, though there is a greater degree of corrosion with thin than with thick covers and more in those concretes containing calcium chloride than in those without".

In the 1955 advice notes of the Cement and Concrete Association [8] to practitioners for concreting in cold weather several precautionary measures are recommended. The extension of curing time and the insulation of the concrete after placing should always be done at low temperatures; however, there is the possibility to accelerate the hardening instead of extension of the curing time. This could be done by (a) the use of an extra-rapid-hardening or rapid-hardening cement or (b) by using an accelerator. Extra-rapid-hardening cement was generally preferred for cold weather work but if it was not possible to use it an accelerator should be added. Calcium chloride was recommended as the most commonly used one. The usual recommended addition was a maximum of $2 \%$ calcium chloride by weight of cement. The type of salt was not specified but the flake form was generally preferred.

The association notes that "Various proprietary accelerators, some based on calcium chloride, are on the market and should generally be used according to the maker's instructions. Some makers, however, have been known to recommend the use of large proportions of their accelerators in very cold weather and this is not good practice".

In addition to the advice on the maximum allowable proportion it was stated that "An accelerator should never be added to extra-rapid-hardening cement. Neither rapid-hardening nor extra-rapid-hardening cements nor accelerators are sufficient alone to protect concrete from frost, and the concrete must be insulated as well."

As early as 1949 and 1955 it was understood that the use of calcium chloride may cause reinforcement corrosion and therefore advice notes were published by government bodies and cement manufacturers and a maximum proportion recommended. However, the calcium chloride producing chemical industry suggested relating the maximum proportion to the air temperature as it is stated in an advice note by the Imperial Chemical Industries [9] (ICI) from 1958. Table 1 gives recommended amounts by the ICI of calcium chloride to be added to the mix. These quantities were not rigidly fixed and may be varied to suit local conditions which could have caused higher proportions. The type of salt recommended was the flake form as it was most easily added directly to the aggregates and cement in the skip of the mixer. 
Table 1: $\quad$ Recommended amounts of calcium chloride, ICI, circa 1958.

\begin{tabular}{ccccc}
\hline Air temperature & \multicolumn{5}{c}{ Percentage weight by mass of cement } \\
\hline & $\% \mathrm{CaCl}_{2}$ & $\% \mathrm{Cl}$ & $\% \mathrm{CaCl}_{2}$ & $\% \mathrm{Cl}$ \\
\hline & Portland cement & Rapid-hardening Portland cement \\
\hline$<32^{\circ} \mathrm{F}\left(<0^{\circ} \mathrm{C}\right)$ & $2.68-3.57$ & $1.71-2.28$ & $1.78-2.68$ & $1.14-1.71$ \\
\hline $32-40^{\circ} \mathrm{F}\left(0-4.4^{\circ} \mathrm{C}\right)$ & 2.68 & 1.71 & 1.34 & 0.86 \\
\hline $\begin{array}{c}40-70^{\circ} \mathrm{F}(4.4- \\
\left.21.1^{\circ} \mathrm{C}\right)\end{array}$ & 1.78 & 1.14 & 0.89 & 1.14 \\
\hline$>70^{\circ} \mathrm{F}\left(>21.1^{\circ} \mathrm{C}\right)$ & $0.89-1.34$ & $0.57-0.86$ & - & - \\
\hline
\end{tabular}

ICI called calcium chloride "a valuable addition to concrete for giving high early strength by accelerating the setting and hardening processes". In its leaflet it explains the effects on the concrete properties and dismisses any negative aesthetic effects caused by efflorescence. The effects of calcium chloride on the reinforcing steel are also discussed and stated as:

"Calcium chloride, under ordinary conditions of curing, forms an insoluble compound with ingredients of the cement, and thus loses its identity and its corrosive nature. Years of experience and extensive practical trials have shown that there is negligible corrosion of the steel in normal in situ reinforced concrete or precast concrete cured at ordinary temperatures, when calcium chloride is used. Experiments continued over a number of years have indicated that such slight corrosion as occurs, appears in the initial stages and is not progressive. When there is insufficient cover or when the concrete is permeable, corrosion can take place with or without the use of calcium chloride.

At the present time some caution is advised in the case of prestressed concrete, in particular that made by systems in which the wet concrete comes in contact with the wires. The small diameter of these leaves a smaller margin for failure by corrosion and one or two failures have been reported which are at present unexplained. A number of possible contributory factors, probably in combination, call for investigation; one of these is the presence of calcium chloride. A programme of research to determine the facts about the use of calcium chloride is being carried out at the Building Research Station. The Cement and Concrete Association is also collaborating in these investigations."

The calcium chloride producing industry acknowledged the corrosive effects on prestressed concrete elements but completely neglected the effects on reinforcing steel and also increased the maximum allowable proportion up to $3.57 \%$ calcium chloride by mass of cement. It should be noted that the limit is very unclear as either the solid or flake form of calcium chloride could be used. It was not explicitly specified until 1968 when it was stated in the Cement and Concrete Association leaflet [10] that "The correct proportion to add is $1.5 \%$ of 
pure calcium chloride by weight of cement, or $2 \%$ of commercial flake calcium chloride which is 70-72\% pure, the remainder being water and other harmless compounds." Ramachandran [11] states that $2 \%$ of the flake form is equivalent to $1.5 \%$ of anhydrous calcium chloride but if $2 \%$ of the anhydrous salt was tolerated then $2.65 \%$ of the dihydrate may have been used.

In the Code of Practice (CP 110) for the structural use of concrete from 1972 it was stated that "In concrete containing embedded metal calcium chloride must not be added in such proportion that the total from the admixture and the total from the aggregates exceeds $1.5 \%$ by weight of cement. Calcium chloride should never be used in prestressed concrete".

\subsection{Detrimental long term effects}

The confusing recommendations with respect to the maximum limit of calcium chloride to be added to the mix and the aim to build fast during all seasons must have contributed to the long term durability issues of reinforced concrete constructed during this period. The statements with respect to corrosive effects give some warning of the potential problems but the real consequences were not properly addressed until much later.

Chlorides can be bound in solid compounds by the cement hydration products; however, the binding ability is limited and finite. The chloride content which can be bound in the hydrate phases depends on several parameters. The literature (e.g. [12-14]) suggests approximately 25 to $50 \%$ of total chlorides can be bound with a maximum threshold of $0.4 \%$ by mass of cement. The remaining chloride ions are freely available in the pore solution. Assuming that calcium chloride was added within its limits of $1.5 \%$ pure calcium chloride then the total internal chloride content of an element would be $1 \% \mathrm{Cl}^{-}$by mass of cement. $0.4 \%$ may be bound but there remains $0.6 \%$ free chloride available.

The free chloride content may increase over time when the concrete carbonates. Carbonation causes a decrease of the normal concrete alkalinity from $\mathrm{pH}$ 12.5-13 towards $\mathrm{pH} 9$ and during this process bound chlorides are released back into solution. If the carbonation front progresses to the depth of the reinforcement the protective layer on the steel destabilizes which may initiate corrosion in the presence of oxygen and moisture. The release of chlorides into the pore solution may exceed the critical chloride threshold and cause corrosion before the carbonation front reaches the reinforcement. The critical chloride threshold is approximately $0.5 \%$ chloride by mass of cement, at which point corrosion is likely to occur. Corrosion of reinforcement causes the formation of voluminous reaction products which can cause spalling and delamination of the concrete cover.

The use of calcium chloride as an accelerator in the past may cause significant deterioration of reinforced concrete structures in the future. If no chlorides from external sources have already initiated corrosion then the relatively slow process of carbonation be the trigger. The time until the carbonation front reaches the reinforcement depends on several parameters. These are mainly the depth of concrete cover and the permeability of the concrete and it may take 100 years or more for the problem to develop. 
In the current standards it is stated that the maximum chloride content of all concrete compounds should not exceed $0.4 \%$ by mass of cement and admixtures should be chloride free. Calcium chloride as an accelerator in reinforced concrete was effectively banned in the UK in 1977 when corrosion first started to be considered seriously.

The Code of Practice CP110 from 1972 was revised in 1977 when a major amendment was made in relation to the use of calcium chloride. "Experience shows that corrosion of prestressing tendons, reinforcement and embedded metal usually results from the combination of factors including excess addition of calcium chloride ... departure from specified mix proportions, poor compaction, inadequate cover and poor detail design." BS 8110:1985 clearly states that "Calcium chloride and chloride-based admixtures should never be added in reinforced concrete, prestressed concrete and concrete containing embedded metal."

\section{Cement}

\subsection{General}

Since the development of the highly successful Portland cement, several other types and variations have been patented. Ordinary Portland cement is the most common type of cement but is not suitable for all environmental conditions such as aggressive soils and solutions. To reduce costs, more economical cements were also desired along with fast hardening cements which could significantly reduce the time of construction.

Portland cement has been blended with slag and pozzolanic materials which also improved the durability. To resist aggressive environments sulphateresisting cements, such as super-sulphated cement and high-alumina cement, were developed, both of which can have problems with respect to durability and repair.

\subsection{Super-sulphated cement}

Super-sulphated cement was invented by Hans Kuehl [15] in 1908 in Germany. It is composed of granulated blastfurnace slag, anhydrite and a small addition of Portland cement. The main advantage of this cement is that it can be manufactured almost without any additional burning processes and therefore many structures were built with this material during and after the war in Germany and Europe [7]. The production ceased in Germany in the 1960s due to the lack of high alumina containing blastfurnace slag. The cement has gained new popularity in recent years because of its low emission manufacturing process.

Structures consisting of super-sulphated cement concrete may create a significant challenge to achieve long lasting repairs. Due to the high sulphate content it is not possible to repair with Portland cement based materials. The risk of sulphate attack at the interface between original substrate and repair mortar may cause significant secondary degradation. 


\subsection{High alumina cement}

High alumina cement (HAC) was developed by Jules Bied in France in 1908 to obtain an alternative to Portland cement with a higher resistance to sulphate attack. It consists of about $40 \%$ each of alumina and lime with around $15 \%$ of ferrous and ferric oxides, plus 5\% silica. The resistance to sulphate attack is due to the absence of $\mathrm{Ca}(\mathrm{OH})_{2}$ in hydrated HAC and also due to the protective influence of the relatively inert alumina gel formed during hydration. HAC is not attacked by $\mathrm{CO}_{2}$ dissolved in pure water, and while it is not acid resisting, it can tolerate very dilute solutions of acids $(\mathrm{pH}>4)$ found in industrial effluents but not hydrochloric, hydrofluoric, or nitric acids. Another positive feature of HAC is its very high rate of strength development. About $80 \%$ of its ultimate strength is reached in 24 hours, and even at 6 to 8 hours the concrete is strong enough for the side formwork to be struck and for the preparation for further concreting to take place. It is for this attribute that it became popular for the production of precast beams used in floor and roofing systems in the late 1960s and early 1970s (Figure 2). However, engineers had already been warned in the code of practice CP114.100 - Suspended concrete floor slabs and roofs from 1950 that "High alumina cement may be unsuitable for use with certain aggregates .... The user can only be guided by previous experience in determining whether it is suitable for use with such aggregates".

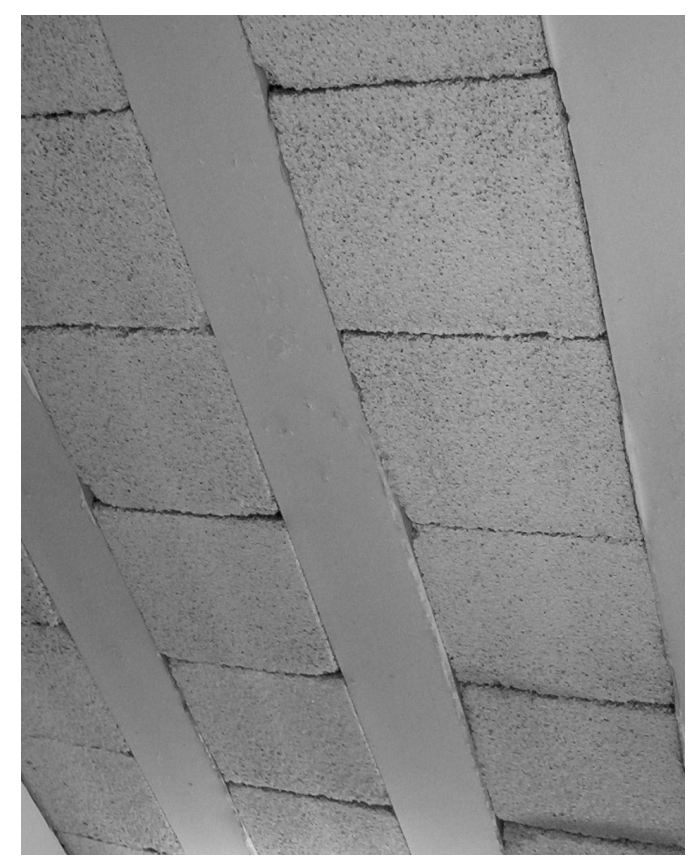

Figure 2: HACC floor beams with block infill still in service in UK, subject to periodic inspection. 
Because a number of high profile catastrophic failures that occurred in the early 1970s, the suitability of HAC concrete (HACC) for use in structural components has been of some considerable concern. The UK's Building Research Establishment (BRE) [16] subsequently carried out a major investigation and identified that $\mathrm{HAC}$ is subject to a process now known as conversion.

The conversion process involves a change in the mineralogy of the cement, which becomes increasingly porous and friable with age and also loses alkalinity. The porosity of the paste increases and therefore the strength of the hydrated cement paste significantly reduces. Also, the increased porosity means the concrete is more susceptible to other forms of attack such as alkali, sulphate attack, or carbonation which may result in reinforcement corrosion.

The effects of conversion on the strength of beams depend on the original strength and quality of concrete used. In some cases, the increase in porosity has been reported to allow moisture to react with unhydrated cement particles and produce an increase in strength. In other cases, significant strength reduction can take place.

Structures were built with HAC concrete until the mid 1970s in the UK and it was banned as a building material in 1976. Most countries on mainland Europe prohibited the use of HAC but France continues to use it to the present day.

Structures which still contain HACC elements are very unlikely to undergo catastrophic failure due to conversion. All conversion processes should have occurred during the last 35 years since the ban was introduced. Deterioration may now be more related to corrosion or alkaline hydrolysis. Structures, which were constructed between the 1920s and the mid 1970s may contain HAC elements, this can include schools, swimming pools and bridges. The type of cement should be identified before any restoration takes place and where appropriate strengthened or replaced.

\subsection{Asbestos cement}

Asbestos cement was developed in the United States in the early 1900s to form a more durable and fire resistant material which was also easier to process, form and install (Hornbostel [17]). At the time it had many economic benefits.

Asbestos cement consists of Portland cement and is reinforced with asbestos fibres of which the content can vary from 10 to $75 \%$. This composite material gained great popularity and its production gradually increased between 1910 and 1940 and then more rapidly until 1960. It was mainly used for roofing, wall cladding, partition walls, panels, water pipes, sewage and underground drainage according to the Health and Safety Executive (HSE) [18].

The asbestos fibres, of which crocidolite, amosite and chrysotile are the main types, are hazardous to people. Breathing in asbestos fibres can lead to asbestosis and lung cancer. The disease can take from 15 to 60 years to develop. Strict regulations have been widely introduced to deal with asbestos in buildings.

Asbestos cement used to be a very variable and much used material in the construction industry until the 1960s in Mainland Europe when it was phased out of production; however, it was not until 1998 that it was also finally banned from 
use in construction works in the UK. Asbestos is still used in many developing countries. In India the 'Asbestos Cement Products Manufacturers Association' (ACPMA) [19] promotes asbestos containing chrysotile fibres as a safe material to be used in cement products. However, nowadays in the western world, asbestos is considered to be a death bringing invention.

\section{Conclusions}

History has taught us that not all human innovations prove successful in the long term. The development of construction methods and materials has been underway since mankind first started to settle. The discovery of the pozzolanic properties of volcano ash led to a first boom of concrete construction but ceased after the fall of the Roman Empire. The demand for a plentiful and readily available building material and the invention of Portland cement led to a second concrete boom which continues to this day.

The only main constituent of concrete which can significantly alter the properties of concrete in the long term is the cementitious element. Admixtures can improve short term properties which are relevant during construction. Water and aggregate are relative fixed constituents. Therefore the focus has been on the cement and admixtures.

Portland cement is the most commonly used binder but not necessarily the most resistant one. Super-sulphated cement and high alumina cement were developed to fulfil these requirements but both cements have caused problems and may be encountered in buildings constructed between 1910 and 1960. The super-sulphated cement is very durable; however, when reinstatement is necessary then it can create major problems if the wrong repair material is used. High alumina cement has already caused several structural failures but it is suggested that the detrimental conversion process should be completed in most structures. There is still the likelihood that HAC structures need to be strengthened. HAC elements are prone to further deterioration processes such as corrosion and improper repair may cause more problems. Asbestos used to be a very useful material to improve the concrete properties but it turned out to bring critical health problems to those handling it without proper protection.

The admixture calcium chloride has proved very useful to improve the properties of fresh concrete so that construction was possible throughout the whole year, even in very cold condition. This was a huge benefit in the short term but in the long term the negative effects, such as degradation due to corrosion, were much greater. Nowadays calcium chloride is effectively banned in most countries from use in concrete, along with asbestos and HAC.

\section{References}

[1] Schaeffer, R.E., Reinforced Concrete, Preliminary design for Architects and Builders; Handout on Skyscrapers, McGraw-Hill Inc., World Book Encyclopedia, 1992. 
[2] Moore, M., Great Wall of China's strength 'comes from sticky rice'. The Telegraph, 30 May 2010.

[3] Encyclopædia Britannica, www.britannica.com/EBchecked/topic/389450/ Joseph-Monier

[4] Legal History and Philosophy, www.commonlaw.com/Hammurabi.html

[5] Kuhl, H. and Ullrich, E., Chloride cracking. Zement, 14, pp.859-861; 880882; 898-901; 917, 1925.

[6] Millar, W. and Nichols, C.F., Improvements in means of accelerating the setting and hardening of cements. Brit. Patent No. 2, 886, March 4, London, England, 1885.

[7] Department of Scientific and Industrial Research, Report of the Building Research Board, 1949.

[8] Cement and Concrete Association, Concreting in cold weather - man on the job leaflet, 1955.

[9] Imperial Chemical Industries Ltd., Calcium chloride - in concrete making. 2nd Edition, Printed by Mears and Caldwell Ltd. London, 1958.

[10] Cement and Concrete Association, Concreting in cold weather - man on the job leaflet, 1968.

[11] Ramachandran, V.S., Calcium chloride in concrete - applications and ambiguities, Canadian Journal of Civil Engineering, V.5, No.2, pp.213-221, 1978.

[12] Richartz, W., Die Bindung von Chlorid bei der Zementerhaertung. ZementKalk-Gips 22, pp.447-456, 1969.

[13] Arya, C., Buenfeld, N.R. and Newman, J.B., Factors influencing chloridebinding in concrete. Cement and Concrete Research 20, pp. 291-300, 1990.

[14] Breit, W., Critical corrosion inducing chloride content - State of the art and new investigation results. Concrete Technology Report. VDZ., 2000.

[15] Kuehl, H., Verfahren zur Herstellung von Zement aus Hochofenschlacke. DRP Nr. 137 777, 23.12.1908.

[16] BRE Digest 392, Assessment of existing high alumina cement concrete construction in the UK, BRE, UK, 1994.

[17] Hornbostel, C., Construction Materials: Types, Uses and Applications, John Wiley and Sons, New York, 1978.

[18] HSE, Working with Asbestos cement. HSG189/2, 1999.

[19] The Asbestos Cement Products Manufacturers Association (ACPMA), www.acpma.com/fact-asbestos.html 